James S. Meyer

William Mackenzie

\section{Malignant bone tumors and limb-salvage surgery in children}

\section{Pediatr Radiol (2004) 34:606-613}

Published online: 26 October 2004 (C) Springer-Verlag 2004

\section{J. S. Meyer}

Department of Medical Imaging,

A.I. duPont Hospital for Children, Wilmington, DE, USA

J. S. Meyer $(\bowtie) \cdot$ W. Mackenzie Jefferson Medical College,

Philadelphia, PA, USA

E-mail: jsmeyer@nemours.org

Tel.: + 1-302-6514686

Fax: + 1-302-6514626

W. Mackenzie

Department of Orthopaedics,

A.I. duPont Hospital for Children,

Wilmington, DE, USA
In this article, Fig. 1c was inadvertently printed twice, once in place of

Fig. 3b. Here is the correct Fig. 3:
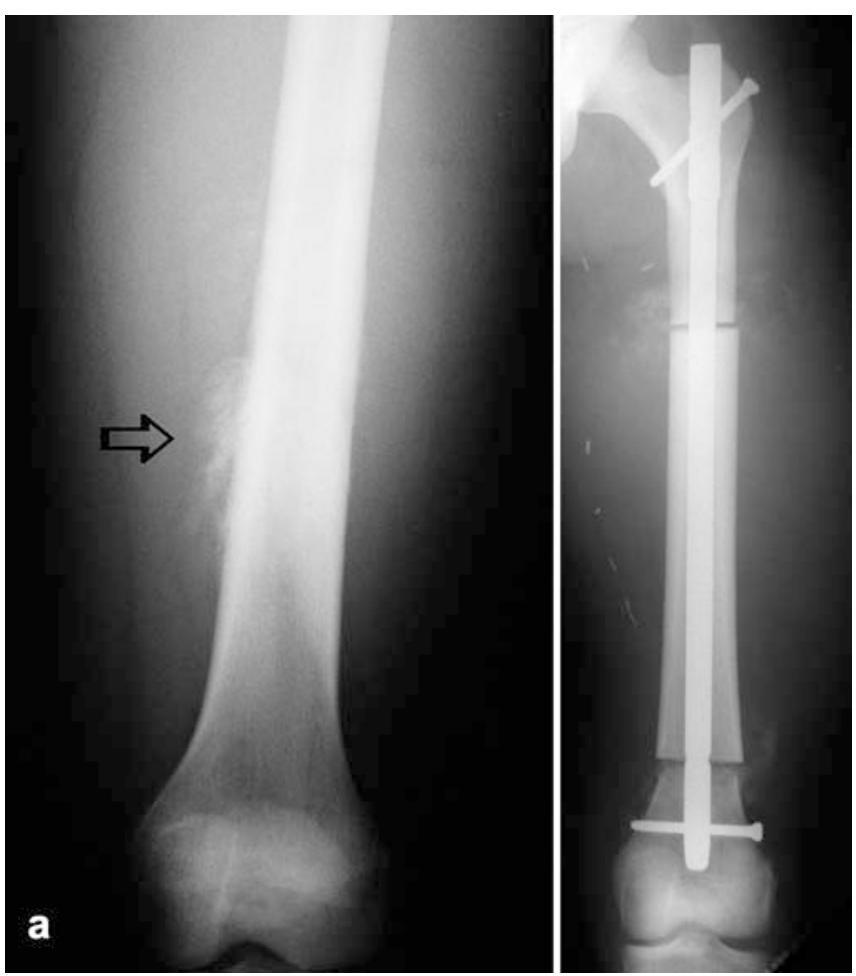

Fig. 3a, b Thirteen-year-old girl with juxtacortical osteosarcoma of distal femur. a AP radiograph shows ossified mass (arrow) at presentation. b AP radiograph following intercalary femoral allograft 